\title{
Thyroid fine-needle aspiration biopsy positively correlates with increased diagnosis of thyroid cancer in South Korean patients
}

\author{
Yoon Jae Cho ${ }^{1 \dagger}$, Do Young Kim ${ }^{1 \dagger}$, Eun-Cheol Park ${ }^{2,3}$ and Kyu-Tae Han ${ }^{2,4^{*}}$
}

\begin{abstract}
Background: The incidence of thyroid cancer among South Koreans is more than 10-fold greater than its incidence in other countries, although its associated mortality rate is similar. Amidst concerns regarding the over-diagnosis of thyroid cancer related to gradually expanded medical testing in South Korea, we hypothesized that the number of thyroid fine-needle aspiration biopsies has led to increased diagnosis of thyroid cancer.

Methods: We used data from the National Health Insurance Service National Sample Cohort 2003-2013, which included all medical claims filed for the 1,122,456 people in a nationally representative sample. We performed a Poisson regression analysis using generalized estimating equation to investigate the relationship between the number of thyroid fine-needle aspiration biopsies and the newly diagnosed cases of thyroid cancer.

Results: The study included 60 annual patients per 100,000 individuals out of 11,024,548 person-years. The number of biopsies per 100,000 patients positively correlated with increased incidence of thyroid cancer diagnosis (per 100 biopsy cases: $R R=1.108 ; 95 \% \mathrm{Cl}: 1.090-1.126 ; P<0.0001)$. Such relationships were greater in males, patients with a higher socioeconomic status, and patients from regions with relatively less accessibility to biopsies.

Conclusion: Our findings suggest that a higher number of thyroid fine-needle aspiration biopsies per 100,000 individuals in a specific Si-Gun-Gu is positively associated with excessively increased diagnosis of thyroid cancer. Regarding the continually increasing thyroid cancer incidence in South Korea, healthcare professionals and policy makers should consider proper guidelines for recognizing the role of thyroid fine-needle aspiration biopsies in the potential over-diagnosis of thyroid cancer.
\end{abstract}

Keywords: Thyroid cancer, Biopsy, Fine-needle, Health Services Accessibility, Overdiagnosis

\section{Background}

South Korea has experienced rapid modernization both socially and economically, leading to the improved health status of South Koreans but an increase of elderly individuals [1, 2]. As a result, the dominant disease patterns of South Koreans shifted from communicable diseases to non-communicable diseases [3], such as

\footnotetext{
* Correspondence: kthan@yuhs.ac

${ }^{\dagger}$ Equal contributors

Institute of Health Services Research, Yonsei University, Seoul, Republic of Korea

${ }^{4}$ Department of Public Health, Graduate School, Yonsei University, Seoul, Republic of Korea

Full list of author information is available at the end of the article
}

cancer $[4,5]$. Many South Koreans now participate in preventive "health checkup" programs, which can positively affect cancer-related health outcomes. However, increased medical testing has led to an unexpected challenge: the "over-diagnosis" of asymptomatic cancers in South Korean individuals [6, 7].

Over-diagnosis occurs when a condition is diagnosed that would otherwise not produce symptoms or cause death [8] and has been tentatively observed with respect to thyroid cancer [9]. According to GLOBOCAN, the incidence of thyroid cancer in South Korea was more than 10 -fold greater than in other countries, although its mortality rate is similar (incidence: 52.8 per 100,000 
South Koreans, 4.0 per 100,000 people worldwide; mortality: 0.5 per 100,000 individuals) $[10,11]$. In addition, the incidence has rapidly increased in South Korea (6.9 vs. 71.3 per 100,000 people in 2000 and 2013, respectively) in parallel with increased medical utilization during this time [12]. Therefore, many healthcare professionals have investigated the possible causes of such rapid increases. The increased incidence of small papillary thyroid cancer with an unchanged mortality rate $[13,14]$ suggests that it may result due to more frequent thyroid cancer screenings, improved diagnostic scrutiny, increased coverage of the National Health Insurance (NHI), more accessibility to ultrasonography, and certain environmental and genetic factors $[6,15]$.

In South Korea, cancer screenings, including thyroid biopsy, are often performed to confirm abnormal findings based on ultrasonography or other clinical indications [16]. According to the National Health Insurance Service (NHIS), the number of thyroid fine-needle aspiration biopsies increased in parallel to the increase in newly diagnosed cases of thyroid cancer [17]. Nevertheless, there are no alternatives for controlling such increases in fineneedle aspiration biopsy and thyroid cancer, and more detailed studies are required to establish effective alternatives for optimal management of thyroid cancer. We hypothesized that the increase in biopsies could significantly affect diagnosis of thyroid cancer, and possibly lead to overdiagnosis. The current study aims to identify an increase in the number of unnecessary thyroid fine-needle aspiration biopsies, and to determine whether it contributes to increasing diagnosis of thyroid cancer.

\section{Methods}

\section{Study population}

The data used in this study were obtained from the NHIS National Sample Cohort 2002-2013 released in 2014 and include a nationally representative random sample of 1,025,340 individuals, approximately $2.2 \%$ of the entire NHIS population in 2002. The data were compiled by the NHIS using a systematic sampling method to generate a representative sample of 46,605,433 Korean residents. The database includes all medical claims filed from January 2002 to December 2013. To investigate the relationship between the number of thyroid fine-needle aspiration biopsies in each geographic region and newly diagnosed cases of thyroid cancer, we excluded patients who were diagnosed with thyroid cancer (ICD-10: C73) before 2003. We then identified patients who underwent a thyroid biopsy (EDI code: C8591) and aggregated this number as a unit of 253 basic administrative districts (Si-Gun-Gu; citycounty-ward) of South Korea. Data used in this study consisted of 11,024,548 person-years of 1,122,456 individuals during 2003-2013.

\section{Variables}

Our outcome variable was the number of newly diagnosed cases of thyroid cancer during the study period, indicated by the first hospital visit during which thyroid cancer (ICD-10: C73) was the major diagnosis for each patient.

The primary independent variable was the number of fine-needle aspiration biopsies performed in each $\mathrm{Si}$ Gun-Gu. We first identified whether patients received thyroid needle aspiration biopsies based on EDI Code and aggregated the number of biopsies as a unit of $\mathrm{Si}$ Gun-Gu per each year. We then calculated the number of biopsies per 100,000 patients using the following formula:

$$
\begin{aligned}
= & \frac{\sum \text { Thyroid fine needle aspiration biopsy in Si-Gun-Gu }}{\text { The number of population in } S i-G u n-G u} \\
& \times 100,000
\end{aligned}
$$

We also adjusted other independent variables when analyzing the association between the number of biopsies per 100,000 people and cases of newly diagnosed thyroid cancer. Other independent variables included sex, age, income, type of insurance coverage, study year, region, and the financial independence rate of the local government. Ages were categorized as $\leq 19,20-29,30-39,40-49,50-$ $59,60-69,70-79$, and $\geq 80$ years to reflect differences in diagnosis of thyroid cancer [18]. The types of insurance coverage were categorized as medical aid, NHI employee insurance, or NHI self-employed insurance based on NHI criteria. Those with NHI employee insurance included workers and employers in all workplaces, public officials, private school employees, continuously insured persons, and daily paid workers at construction sites. Beneficiaries of NHI employee insurance included spouses, descendants, siblings, and parents. Individuals with NHI employee insurance paid approximately $7 \%$ of their average salary in contribution payments, though these rates usually changed annually. The NHI self-employed insurance category included people whose contribution amount was set based on their income, property, living standard, and rate of participation in economic activities. Medical aid beneficiaries were patients with an income below the government-defined poverty level or who had a disability and were provided with free in- and outpatient care via government funds. Therefore, the type of insurance coverage represented each patient's socioeconomic status [2]. We included this variable in the study to consider potential differences in the accessibility of thyroid cancer screening according to socioeconomic status. The financial independence rate of the local government was an index of the finance utilization capacity of a local government with independent discretionary power, which was 
calculated as: (local taxes + non-tax revenue)/local government budgets $\times 100$ [19].

\section{Statistical analysis}

We first examined the frequencies and percentages of each categorical variable or the mean and standard deviation of each continuous variable at each patient's baseline, respectively. We performed $x^{2}$ tests to analyze the distribution of person-years for each categorical variable by diagnosis of thyroid cancer and an analysis of variance (ANOVA) for each continuous variable by diagnosis during the study period. The tests were performed in all study subjects and patients who received thyroid biopsy, respectively. Finally, we performed Poisson regression analysis using generalized estimating equations (GEE) to investigate the relationship between the number of thyroid biopsies and cases of newly diagnosed thyroid cancer adjusting for sex, age, income, type of insurance coverage, study year, region, and financial independence rate of regional government. GEE models with link logit that included both patient- and regionlevel variables were analyzed, as data used in this study were hierarchically structured and had binary outcome variables. This model assumed proper distributions for each hospitalization case while taking into account the correlation among individuals within the Si-Gun-Gu. In this study, the correlation was an exchangeable correlation structure [20]. To identify whether thyroid biopsies were unnecessary for diagnosis of thyroid cancer, we also analyzed the relationship between the number of thyroid biopsies and newly diagnosed thyroid cancer cases only among patients who received thyroid biopsies. The goodness-of-fit for the GEE model was assessed using the quasi-likelihood under the independence criterion (QIC), whose lower value indicated the goodness-of-fit [21]. In addition, we performed sub-group analyses for Poisson regression analyses to compare differences in the association between the number of biopsies and cases of newly diagnosed thyroid cancer according to sex, income, the median number of thyroid fine-needle biopsies, and financial independence rate of the local government. All statistical analyses were performed using SAS version 9.4.

\section{Results}

The data used in this study were compiled from $1,122,456$ people at baseline and represented 11,024,548 person-years during the study period. Additional file 1 shows the patients' general characteristics, including individual- and regional-level variables at baseline. The average follow-up period of each person included in this study was 9.82 person-years. The average number of thyroid fine-needle aspiration biopsies in each $\mathrm{Si}-\mathrm{Gun}-\mathrm{Gu}$ at baseline was 73.16 per 100,000 individuals. There were generally more individuals in the lower age group than in the older age groups. "NHI employed" was the most common type of insurance coverage. Figure 1 shows trends of the incidence and mortality of thyroid cancer during the study period. The incidence gradually increased, but the mortality rate remained relatively stable. Figure 2 shows the positive correlation between number of thyroid fine-needle aspiration biopsies and new diagnoses of thyroid cancer during the study period (Spearman correlation coefficient: $0.48, P<0.001$ ).

Table 1 shows the associations between new cases of thyroid cancer and each independent variable in this study. We observed a $0.6 \%$ incidence rate $(n=6619$ diagnosed patients) among $11,024,548$ person-years, and the average number of thyroid fine needle biopsies in Si-Gun$\mathrm{Gu}$ was greater in patients diagnosed with thyroid cancer than in patients who were not diagnosed (Diagnosed mean: 348.2, SD: 225.0; Non-diagnosed mean: 253.3, SD: 207.9; $P<0.0001$ ). In addition, socioeconomic status had a positive linear association with thyroid cancer diagnosis. By region, patients from Jeollanam-do were more frequently with thyroid cancer than patients from other regions. On the other hand, in regards to patients with thyroid biopsy, the average number of thyroid fine-needle biopsies performed in Si-Gun-Gu was lower in patients diagnosed with thyroid cancer compared to others.

Table 2 shows the results of GEE Poisson regression analyses for the entire population and for patients with thyroid needle biopsy, respectively. In the whole population, the number of biopsies per 100,000 individuals was positively associated with diagnosis of thyroid cancer (per 100 cases: $R R=1.108,95 \%$ CI: $1.090-1.126 ; P<0.0001)$. The financial independence rate of the local government was also positively associated with increased diagnosis of thyroid cancer but it was not statistically significant. Diagnosed cases of thyroid cancer in females were 5 -fold greater than males, and patients 40-59 years of age were more often diagnosed than patients of other age groups. Patients of higher socioeconomic status showed a greater incidence of thyroid cancer diagnosis. In addition, the risk in the diagnosis of thyroid cancer was gradually increased by the year. In patients who received thyroid biopsy, in contrast to results from the entire population, the regional number of thyroid fineneedle aspiration biopsy was inversely associated with the diagnosis of thyroid cancer (per 100 cases: $R R=0.973$, 95\% CI: 0.952-0.995; $P=0.0143)$. In particular, patients under 40 years of age were more often diagnosed than patients in other age groups.

We also performed subgroup analyses to investigate positive associations in the number of biopsies with thyroid cancer diagnoses according to sex, income, median number of thyroid fine-needle biopsy, and financial independence rate of local government (Fig. 3). In the whole 


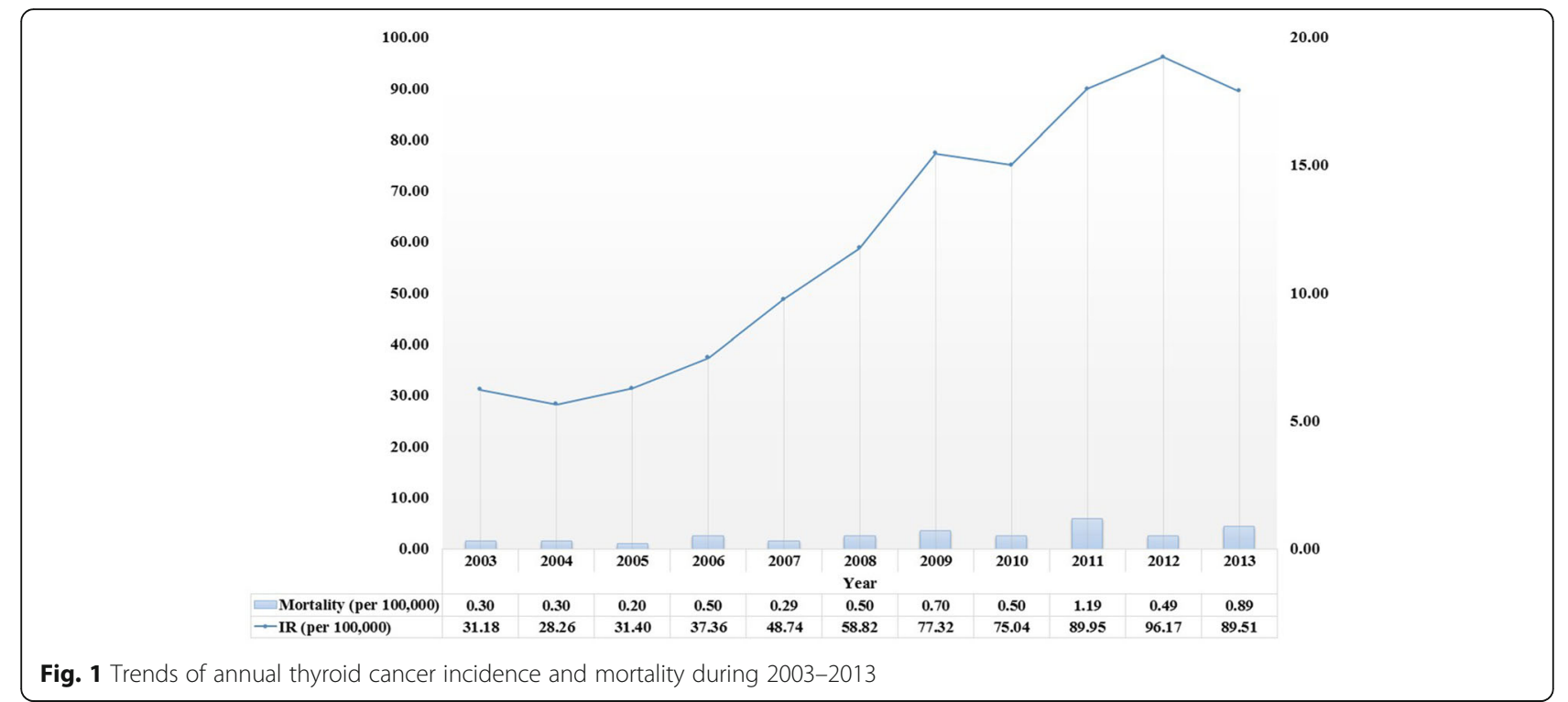

population, positive association was greater in males than females, in patients with incomes above the median financial independence rate, and in subjects from regions with lower biopsy frequencies than the median number. On the other hand, for patients who received thyroid biopsy, negative association was observed more in females as well as in patients with incomes below the median financial independence rate (Fig. 4).

\section{Discussion}

The rapid improvement of health status in South Korean has created an "aging society" in which dominant health problems and issues have shifted to non-communicable diseases, such as cancer. Although many healthcare professionals have prompted positive outcomes through improved medical care [4], some concerns regarding the over-diagnosis of certain diseases, such as thyroid cancer, have arisen and have been validated in previous studies [7]. For example, previous studies suggest that increased access to ultrasonography in South Korea could contribute to increased cases of thyroid cancer [6]. However, questions remain regarding the environmental and genetic factors that may prompt the over-diagnosis of thyroid cancer.

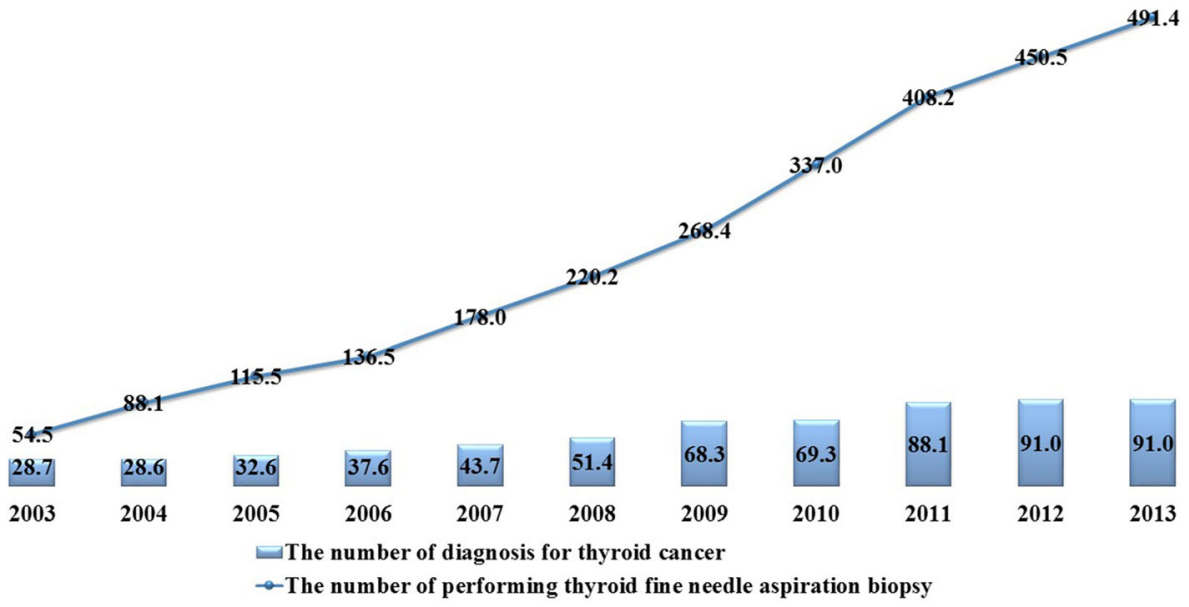

Fig. 2 Correlation between thyroid fine-needle aspiration biopsy frequency and diagnosis of thyroid cancer during 2003-2013. *Each indicator was calculated as the number of thyroid fine-needle aspiration biopsy or diagnosis of thyroid cancer per 100,000 individuals in Si-Gun-Gu 
Table 1 Distribution of person-years by diagnosis of thyroid cancer

\begin{tabular}{|c|c|c|c|c|c|c|c|c|c|c|}
\hline \multirow[t]{3}{*}{ Variables } & \multicolumn{5}{|c|}{ Total patients } & \multicolumn{5}{|c|}{$\begin{array}{l}\text { Patients with thyroid fine-needle } \\
\text { aspiration biopsy }\end{array}$} \\
\hline & \multicolumn{2}{|c|}{ Diagnosed } & \multicolumn{2}{|l|}{ None } & \multirow[t]{2}{*}{$P$-value } & \multicolumn{2}{|c|}{ Diagnosed } & \multicolumn{2}{|l|}{ None } & \multirow[t]{2}{*}{$P$-value } \\
\hline & N/Mean & $\% / S D$ & N/Mean & $\% / S D$ & & N/Mean & $\% / S D$ & N/Mean & $\% / S D$ & \\
\hline \multicolumn{11}{|l|}{ Regional variables } \\
\hline $\begin{array}{l}\text { Number of thyroid fine-needle aspiration biopsies } \\
\text { in Si-Gun-Gu (per 100,000 people) }\end{array}$ & 348.2 & 225.0 & 253.3 & 207.9 & $<0.0001^{\mathrm{a}}$ & 348.2 & 225.0 & 425.9 & 236.8 & $<.0001^{\mathrm{a}}$ \\
\hline Financial independence rate of local government (\%) & 62.2 & 23.3 & 62.4 & 23.6 & $0.5344^{\mathrm{a}}$ & 62.2 & 23.3 & 59.4 & 22.9 & $<.0001^{\mathrm{a}}$ \\
\hline \multicolumn{11}{|l|}{ Individual variables } \\
\hline \multicolumn{11}{|l|}{ Sex } \\
\hline Male & 1140 & 0.02 & $5,514,264$ & 99.98 & $<0.0001^{b}$ & 1140 & 22.04 & 4033 & 77.96 & $0.1968^{b}$ \\
\hline Female & 5479 & 0.10 & $5,503,665$ & 99.90 & & 5479 & 21.23 & 20,327 & 78.77 & \\
\hline \multicolumn{11}{|l|}{ Age (years) } \\
\hline 0-19 & 30 & 0.00 & $2,622,533$ & 100.00 & $<0.0001^{b}$ & 30 & 21.58 & 109 & 78.42 & $<0.0001^{\mathrm{b}}$ \\
\hline $20-29$ & 339 & 0.02 & $1,580,567$ & 99.98 & & 339 & 26.26 & 952 & 73.74 & \\
\hline $30-39$ & 1210 & 0.07 & $1,866,884$ & 99.94 & & 1210 & 26.86 & 3295 & 73.14 & \\
\hline $40-49$ & 1972 & 0.10 & $1,909,614$ & 99.90 & & 1972 & 23.69 & 6352 & 76.31 & \\
\hline $50-59$ & 1819 & 0.13 & $1,392,449$ & 99.87 & & 1819 & 19.48 & 7519 & 80.52 & \\
\hline $60-69$ & 876 & 0.10 & 894,668 & 99.90 & & 876 & 16.65 & 4386 & 83.35 & \\
\hline $70-79$ & 320 & 0.06 & 543,227 & 99.94 & & 320 & 16.82 & 1582 & 83.18 & \\
\hline $80+$ & 53 & 0.03 & 207,987 & 99.98 & & 53 & 24.31 & 165 & 75.69 & \\
\hline \multicolumn{11}{|l|}{ Type of insurance coverage } \\
\hline Medical Aid & 144 & 0.04 & 383,596 & 99.96 & $<0.0001^{\mathrm{b}}$ & 144 & 34.37 & 275 & 65.63 & $<0.0001^{\mathrm{b}}$ \\
\hline NHI (self-employed) & 2142 & 0.05 & $4,060,517$ & 99.95 & & 2142 & 21.69 & 7734 & 78.31 & \\
\hline NHI (employed) & 4333 & 0.07 & $6,573,816$ & 99.93 & & 4333 & 20.95 & 16,351 & 79.05 & \\
\hline \multicolumn{11}{|l|}{ Income (percentiles) } \\
\hline $0-29 \%$ & 873 & 0.05 & $1,784,071$ & 99.95 & $<0.0001^{b}$ & 873 & 20.45 & 3395 & 79.55 & $0.2938^{b}$ \\
\hline $30-59 \%$ & 1310 & 0.05 & $2,612,723$ & 99.95 & & 1310 & 21.49 & 4785 & 78.51 & \\
\hline $60 \%+$ & 4436 & 0.07 & $6,621,135$ & 99.93 & & 4436 & 21.52 & 16,180 & 78.48 & \\
\hline \multicolumn{11}{|l|}{ Year } \\
\hline 2003 & 317 & 0.03 & $1,016,565$ & 99.97 & $<0.0001^{\mathrm{b}}$ & 317 & 40.80 & 460 & 59.20 & $<0.0001^{\mathrm{b}}$ \\
\hline 2004 & 287 & 0.03 & $1,015,716$ & 99.97 & & 287 & 26.70 & 788 & 73.30 & \\
\hline 2005 & 319 & 0.03 & $1,015,929$ & 99.97 & & 319 & 23.74 & 1025 & 76.26 & \\
\hline 2006 & 374 & 0.04 & $1,001,078$ & 99.96 & & 374 & 23.29 & 1232 & 76.71 & \\
\hline 2007 & 497 & 0.05 & $1,019,688$ & 99.95 & & 497 & 22.42 & 1720 & 77.58 & \\
\hline 2008 & 588 & 0.06 & 999,651 & 99.94 & & 588 & 22.13 & 2069 & 77.87 & \\
\hline 2009 & 771 & 0.08 & 997,219 & 99.92 & & 771 & 24.12 & 2425 & 75.88 & \\
\hline 2010 & 751 & 0.08 & $1,000,753$ & 99.93 & & 751 & 19.37 & 3126 & 80.63 & \\
\hline 2011 & 884 & 0.09 & 983,859 & 99.91 & & 884 & 20.49 & 3430 & 79.51 & \\
\hline 2012 & 941 & 0.10 & 983,065 & 99.90 & & 941 & 19.37 & 3918 & 80.63 & \\
\hline 2013 & 890 & 0.09 & 984,406 & 99.91 & & 890 & 17.60 & 4167 & 82.40 & \\
\hline \multicolumn{11}{|l|}{ Region (distance from Seoul) } \\
\hline Gangwon-do (100.6 km) & 115 & 0.04 & 321,209 & 99.96 & $<0.0001^{b}$ & 115 & 20.25 & 453 & 79.75 & $<0.0001^{\mathrm{b}}$ \\
\hline Gyeonggi-do (40.0km) & 1445 & 0.06 & $2,528,926$ & 99.94 & & 1445 & 21.80 & 5182 & 78.20 & \\
\hline Gyeongsangnam-do (366.4km) & 335 & 0.05 & 653,458 & 99.95 & & 335 & 20.68 & 1285 & 79.32 & \\
\hline
\end{tabular}


Table 1 Distribution of person-years by diagnosis of thyroid cancer (Continued)

\begin{tabular}{|c|c|c|c|c|c|c|c|c|}
\hline Gyeongsangbuk-do (225.5km) & 303 & 0.05 & 595,692 & 99.95 & 303 & 22.35 & 1053 & 77.65 \\
\hline Gwangju (295.3km) & 272 & 0.08 & 324,124 & 99.92 & 272 & 14.48 & 1607 & 85.52 \\
\hline Daegu (288.3 km) & 432 & 0.08 & 561,837 & 99.92 & 432 & 17.63 & 2019 & 82.37 \\
\hline Daejeon (160.9 km) & 267 & 0.08 & 334,572 & 99.92 & 267 & 28.13 & 682 & 71.87 \\
\hline Busan (394.2 km) & 440 & 0.05 & 807,140 & 99.95 & 440 & 19.32 & 1837 & 80.68 \\
\hline Seoul & 1504 & 0.07 & $2,282,278$ & 99.93 & 1504 & 24.78 & 4566 & 75.22 \\
\hline Ulsan (395.7 km) & 184 & 0.07 & 259,663 & 99.93 & 184 & 24.02 & 582 & 75.98 \\
\hline Incheon (37.7 km) & 265 & 0.04 & 606,840 & 99.96 & 265 & 23.47 & 864 & 76.53 \\
\hline Jeollanam-do (346.3km) & 382 & 0.09 & 429,219 & 99.91 & 382 & 17.54 & 1796 & 82.46 \\
\hline Jeollabuk-do (216.9km) & 244 & 0.06 & 413,454 & 99.94 & 244 & 18.26 & 1092 & 81.74 \\
\hline Jeju-do (541.6 km) & 69 & 0.06 & 123,336 & 99.94 & 69 & 23.31 & 227 & 76.69 \\
\hline Chungcheongnam-do (129.9km) & 226 & 0.05 & 437,945 & 99.95 & 226 & 24.73 & 688 & 75.27 \\
\hline Chungcheongbuk-do (137.1km) & 136 & 0.04 & 338,236 & 99.96 & 136 & 24.16 & 427 & 75.84 \\
\hline Total & 6619 & 0.06 & $11,017,929$ & 99.98 & 6619 & 21.37 & 24,360 & 78.63 \\
\hline
\end{tabular}

${ }^{a}$ The results of analysis of variance (ANOVA) for each continuous variable to compare mean and standard deviation by diagnosis during study period

${ }^{\mathrm{b}}$ The results of $\mathrm{X} 2$ tests to analyze frequencies of person-years for each categorical variable by diagnosis of thyroid cancer

We focused on the relationship between thyroid biopsies and newly diagnosed cases of thyroid cancer using nationwide sampling data and identified a positive correlation. Our results corroborate those of previous studies regarding the role of certain diagnostic tests, such as ultrasonography, in increased thyroid cancer diagnoses [22]. However, thyroid ultrasonography is not included under NHI coverage. Although increased diagnoses could be a natural result of more frequent screening procedures [23, 24], the increased diagnosis of small papillary thyroid cancer and other nonfatal thyroid cancers should still be investigated in South Korea because of a concomitant increase in preventive medical procedures and changes in thyroid cancer biopsy criteria [25]. However, regarding the more thyroid fineneedle aspiration biopsy were inversely associated with diagnosis of thyroid cancer among patients who received these biopsy, there might be excessive medical screening such as biopsy compared to actual diagnosis. Thus, there are needed to optimal control for guideline related to implementation of biopsy even if there were some controversies related to that.

The results of our sub-group analyses support our hypothesis, as the positive association between biopsy frequency and new cases of thyroid cancer was greater in patients with higher socioeconomic status, suggesting that greater accessibility to certain screening tests directly influences the frequency of cancer diagnosis [15]. Also, in the results for sub-group analysis by sex, regarding the incidence of thyroid cancer in females was higher than males based on previous studies, the increasing thyroid biopsy might cause to unnecessary increasing the diagnosis of thyroid cancer based on the greater positive correlations with diagnosis of thyroid cancer in males [18]. Meanwhile, subgroup analysis results for patients with biopsy showed that female patients and patients from low economic status areas had less diagnosis of thyroid cancer, in contrast to increase in regional biopsy. The results also suggested that unnecessary biopsy may be provided for patients at high risk of thyroid cancer or those with less health information.

Our study's strengths include the use of national sampling cohort data to identify the relationship between the number of thyroid fine-needle aspiration biopsies and increased diagnoses of thyroid cancer. Therefore, our results are especially helpful for establishing evidence-based policies for managing thyroid cancer. Second, to our knowledge, this study is the first published attempt to investigate the impact of thyroid fine-needle aspiration biopsy frequency in individual geographic regions with respect to new cases of thyroid cancer. Previous studies focused on increased thyroid cancer incidence and changes in cancer type according to year or due to increased ultrasonography availability [6]. Thus, our findings could suggest another factor that contributes to more new thyroid cancer cases in South Korea. Third, our study analyzed the relationship between thyroid biopsies and thyroid cancer diagnoses adjusting for other covariates, such as socioeconomic status. Although other studies have linked increased thyroid cancer with differences in socioeconomic-related healthcare accessibility [15], we further analyzed the effects of income level, type of insurance coverage, and financial independence rate of the local government in this study. 
Table 2 Poisson regression analysis results for diagnosis for thyroid cancer

\begin{tabular}{|c|c|c|c|c|c|c|c|c|}
\hline \multirow[t]{2}{*}{ Variables } & \multicolumn{4}{|c|}{ Total patients } & \multicolumn{4}{|c|}{$\begin{array}{l}\text { Patients with thyroid } \\
\text { fine-needle aspiration biopsy }\end{array}$} \\
\hline & \multirow[t]{2}{*}{$\overline{\mathrm{RR}^{\mathrm{a}}}$} & \multicolumn{2}{|l|}{$95 \% \mathrm{Cl}$} & \multirow[t]{2}{*}{$P$-value } & \multirow[t]{2}{*}{$\overline{\mathrm{RR}^{\mathrm{a}}}$} & \multicolumn{2}{|l|}{$95 \% \mathrm{Cl}$} & \multirow[t]{2}{*}{$P$-value } \\
\hline Regional variables & & & & & & & & \\
\hline $\begin{array}{l}\text { Number of thyroid fine-needle aspiration biopsy in Si-Gun-Gu } \\
\text { (per 100,000 people; per } 100 \text { increase) }\end{array}$ & 1.108 & 1.090 & 1.126 & $<0.0001$ & 0.973 & 0.952 & 0.995 & 0.0143 \\
\hline Financial independence rate of local government (per 10\%) & 1.037 & 0.955 & 1.125 & 0.3849 & 1.003 & 0.992 & 1.015 & 0.5599 \\
\hline \multicolumn{9}{|l|}{ Individual variables } \\
\hline \multicolumn{9}{|l|}{ Sex } \\
\hline Male & 0.206 & 0.194 & 0.220 & $<0.0001$ & 1.075 & 0.990 & 1.168 & 0.0852 \\
\hline Female & 1.000 & - & - & - & 1.000 & - & - & - \\
\hline \multicolumn{9}{|l|}{ Age (years) } \\
\hline 0-19 & 0.059 & 0.038 & 0.093 & $<0.0001$ & 1.359 & 0.703 & 2.627 & 0.3613 \\
\hline $20-29$ & 1.155 & 0.864 & 1.543 & 0.3313 & 1.700 & 1.065 & 2.713 & 0.0263 \\
\hline $30-39$ & 3.334 & 2.532 & 4.391 & $<0.0001$ & 1.796 & 1.142 & 2.824 & 0.0113 \\
\hline $40-49$ & 5.389 & 4.100 & 7.082 & $<0.0001$ & 1.519 & 0.968 & 2.385 & 0.0689 \\
\hline $50-59$ & 6.430 & 4.892 & 8.450 & $<0.0001$ & 1.219 & 0.776 & 1.913 & 0.3897 \\
\hline $60-69$ & 4.721 & 3.578 & 6.230 & $<0.0001$ & 0.921 & 0.584 & 1.453 & 0.7245 \\
\hline 70-79 & 2.542 & 1.901 & 3.398 & $<0.0001$ & 0.858 & 0.535 & 1.376 & 0.5248 \\
\hline $80+$ & 1.000 & - & - & - & 1.000 & - & - & - \\
\hline \multicolumn{9}{|l|}{ Type of insurance coverage } \\
\hline Medical Aid & 0.768 & 0.642 & 0.919 & 0.0040 & 1.466 & 1.101 & 1.952 & 0.0087 \\
\hline NHI (self-employed) & 0.785 & 0.745 & 0.827 & $<0.0001$ & 1.014 & 0.947 & 1.085 & 0.6984 \\
\hline NHI (employed) & 1.000 & - & - & - & 1.000 & - & - & - \\
\hline \multicolumn{9}{|l|}{ Income (percentiles) } \\
\hline $0-29 \%$ & 0.640 & 0.591 & 0.692 & $<0.0001$ & 0.879 & 0.794 & 0.974 & 0.0135 \\
\hline $30-59 \%$ & 0.725 & 0.682 & 0.771 & $<0.0001$ & 0.965 & 0.892 & 1.045 & 0.3839 \\
\hline $60 \%+$ & 1.000 & - & - & - & 1.000 & - & - & - \\
\hline \multicolumn{9}{|l|}{ Year } \\
\hline 2003 & 1.000 & - & - & - & 1.000 & - & - & - \\
\hline 2004 & 0.853 & 0.727 & 1.001 & 0.0517 & 0.784 & 0.597 & 1.029 & 0.0795 \\
\hline 2005 & 0.907 & 0.776 & 1.060 & 0.2187 & 0.770 & 0.593 & 1.000 & 0.0500 \\
\hline 2006 & 1.029 & 0.885 & 1.197 & 0.7092 & 0.878 & 0.686 & 1.125 & 0.3051 \\
\hline 2007 & 1.258 & 1.086 & 1.456 & 0.0022 & 0.924 & 0.727 & 1.174 & 0.5179 \\
\hline 2008 & 1.438 & 1.243 & 1.664 & $<0.0001$ & 0.927 & 0.730 & 1.178 & 0.5372 \\
\hline 2009 & 1.765 & 1.530 & 2.035 & $<0.0001$ & 1.023 & 0.807 & 1.297 & 0.8505 \\
\hline 2010 & 1.583 & 1.361 & 1.842 & $<0.0001$ & 0.870 & 0.680 & 1.112 & 0.2646 \\
\hline 2011 & 1.757 & 1.509 & 2.045 & $<0.0001$ & 1.026 & 0.804 & 1.309 & 0.8379 \\
\hline 2012 & 1.725 & 1.477 & 2.015 & $<0.0001$ & 1.041 & 0.813 & 1.332 & 0.7510 \\
\hline 2013 & 1.579 & 1.345 & 1.854 & $<0.0001$ & 1.067 & 0.830 & 1.371 & 0.6152 \\
\hline \multicolumn{9}{|l|}{ Region (distance from Seoul) } \\
\hline Gangwon-do (100.6 km) & 1.001 & 0.662 & 1.515 & 0.9960 & 0.999 & 0.557 & 1.789 & 0.9959 \\
\hline Gyeonggi-do (40.0km) & 1.192 & 1.042 & 1.364 & 0.0107 & 0.955 & 0.792 & 1.151 & 0.6277 \\
\hline Gyeongsangnam-do (366.4km) & 1.234 & 0.925 & 1.647 & 0.1526 & 1.130 & 0.760 & 1.680 & 0.5457 \\
\hline Gyeongsangbuk-do (225.5km) & 1.293 & 0.882 & 1.897 & 0.1879 & 1.322 & 0.777 & 2.249 & 0.3028 \\
\hline Gwangju (295.3km) & 1.435 & 1.124 & 1.832 & 0.0037 & 0.882 & 0.634 & 1.226 & 0.4537 \\
\hline
\end{tabular}


Table 2 Poisson regression analysis results for diagnosis for thyroid cancer (Continued)

\begin{tabular}{lllllllll}
\hline Daegu (288.3 km) & 1.325 & 1.099 & 1.598 & 0.0032 & 1.106 & 0.850 & 1.437 & 0.4539 \\
Daejeon (160.9 km) & 1.735 & 1.451 & 2.075 & $<0.0001$ & 1.445 & 1.130 & 1.848 & 0.0033 \\
Busan (394.2 km) & 1.048 & 0.883 & 1.244 & 0.5927 & 1.238 & 0.974 & 1.574 & 0.0810 \\
Seoul & 1.238 & 1.003 & 1.528 & 0.0468 & 1.038 & 0.776 & 1.388 & 0.7999 \\
Ulsan (395.7 km) & 1.354 & 1.121 & 1.636 & 0.0017 & 1.370 & 1.074 & 1.746 & 0.0111 \\
Incheon (37.7 km) & 1.000 & - & - & - & & & \\
Jeollanam-do (346.3 km) & 1.774 & 1.150 & 2.737 & 0.0095 & 1.387 & 0.751 & 2.562 & 0.2954 \\
Jeollabuk-do (216.9 km) & 1.398 & 0.924 & 2.113 & 0.1125 & 1.263 & 0.710 & 2.245 & 0.4275 \\
Jeju-do (541.6 km) & 1.535 & 0.996 & 2.366 & 0.0522 & 1.436 & 0.794 & 2.598 & 0.2315 \\
Chungcheongnam-do (129.9 km) & 1.383 & 0.982 & 1.946 & 0.0633 & 1.239 & 0.772 & 1.990 & 0.3746 \\
Chungcheongbuk-do (137.1 km) & 1.130 & 0.780 & 1.636 & 0.5188 & 0.960 & 0.564 & 1.634 & 0.8805 \\
QIC & 99756.63 & & & & 24319.41 &
\end{tabular}

${ }^{a}$ Relative risk for diagnosis of thyroid cancer, based on the results of Poisson regression analysis with GEE adjusted for individual- and regional-level characteristic to identify the relationship between regional thyroid fine-needle biopsy rates and diagnosis of thyroid cancer

Our study also has limitations. First, previous studies considered the types and size of thyroid cancer and accessibility to ultrasonography as important factors in over-diagnosis. However, we were unable to include these variables because these data were not available in the NHI database. Second, to identify overdiagnosis of cancer, information such as types and stages of thyroid cancer would be important. However, due to limited data, we could not identify such factors. Third, patients' participation in the health checkup program could contribute to over-diagnosis of thyroid cancer, but we could not identify which patients were diagnosed with thyroid cancer through this program due to data limitations, even though incidence rates increased by year. Finally, income level data were only collected as units of 10th percentiles. Because income level appears to be a significant factor in thyroid cancer over-diagnosis, more specific income information for each patient could strengthen are study.

Despite these limitations, our findings suggest that increased numbers of thyroid fine- needle aspiration biopsies per 100,000 patients by geographic region could contribute to increased diagnoses of thyroid cancer in South Korea. Specifically, such relationships were more significant in

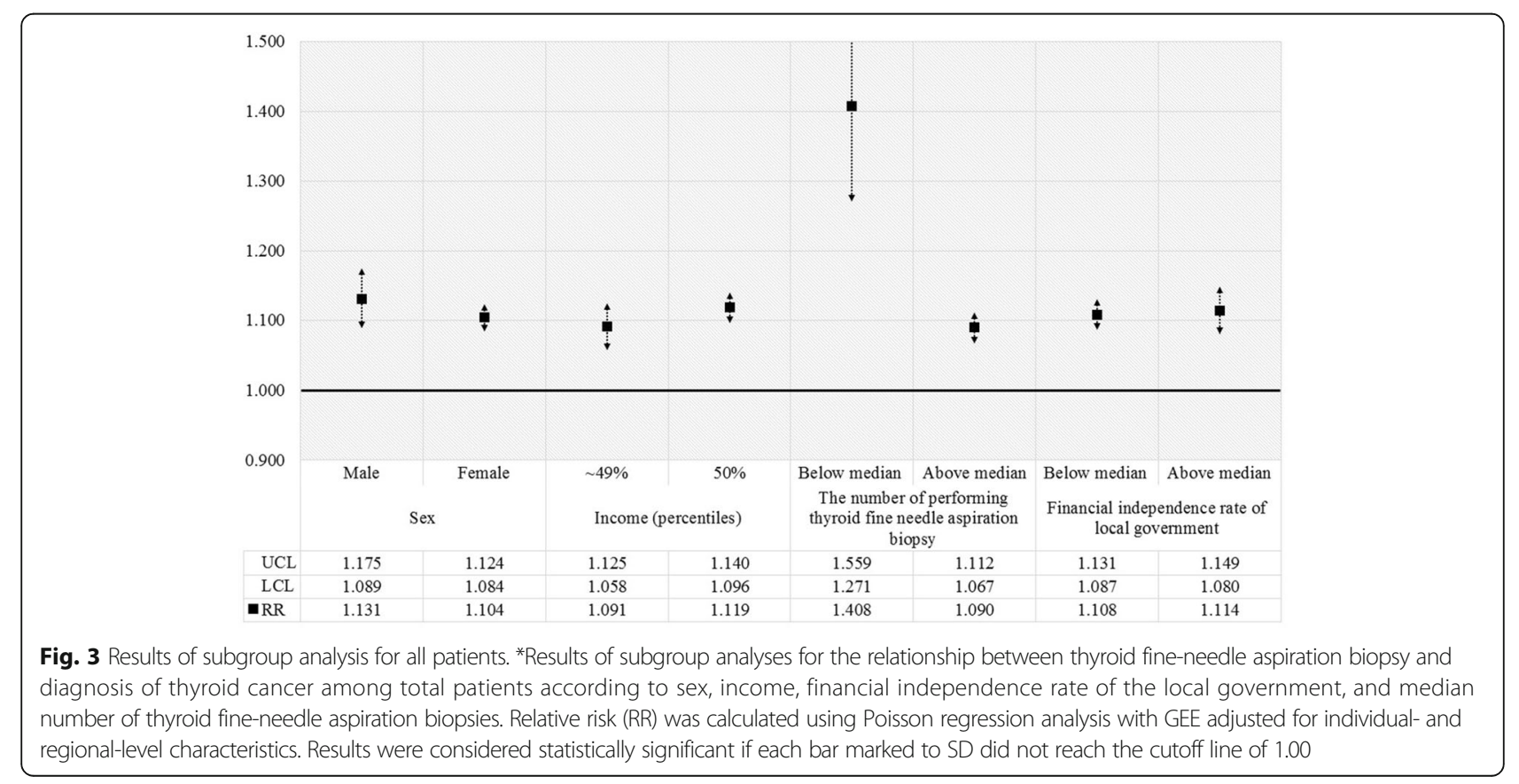




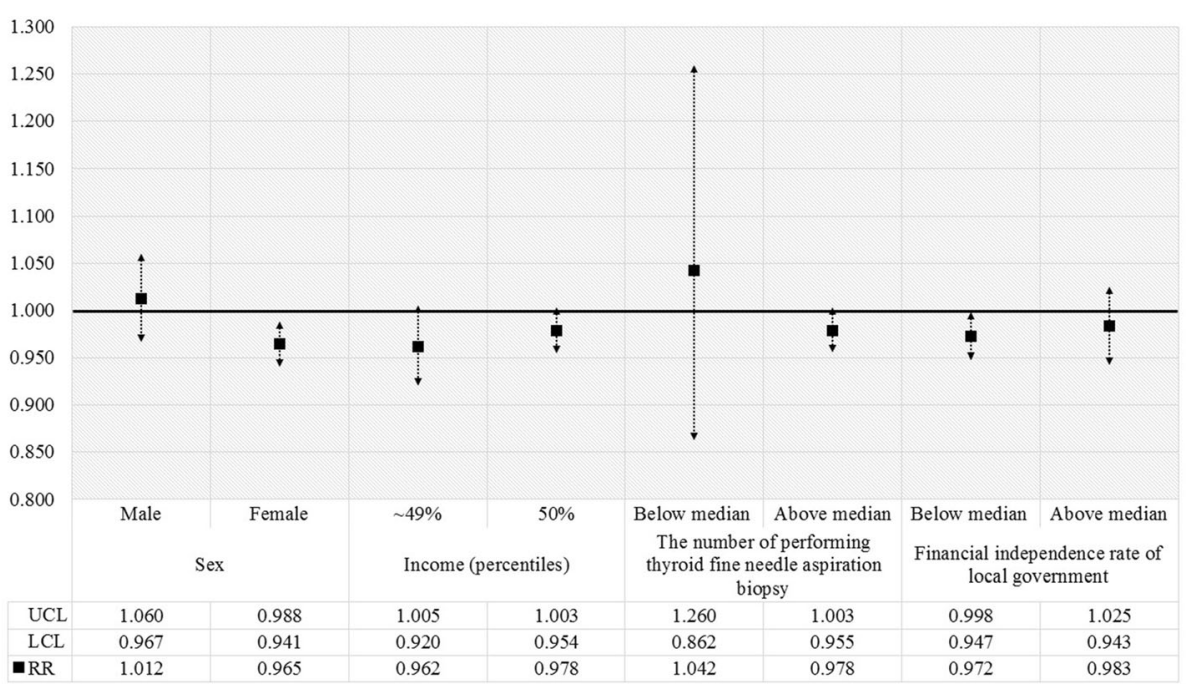

Fig. 4 Results of subgroup analysis for patients who underwent thyroid fine-needle biopsy. ${ }^{*}$ Results of subgroup analyses for the relationship between thyroid fine-needle aspiration biopsy and diagnosis of thyroid cancer only among patients who underwent thyroid fine-needle biopsy according to sex, income, financial independence rate of the local government, and median number of thyroid fine-needle aspiration biopsies. Relative risk (RR) was calculated by Poisson regression analysis with GEE adjusted for individual- and regional-level characteristics. Results were considered statistically significant if each bar marked to SD did not reach the cutoff line of 1.00

males, patients with higher socioeconomic status, and in patients from regions with relatively less accessibility to biopsies. In addition, we also found that some excessive biopsies might be provided for people without increasing diagnosis among patients who received biopsies. The increased incidence of new thyroid cancer cases by year necessitates guidelines for optimal control and diagnosis of thyroid cancer and should prompt healthcare professionals and policy makers to consider the factors that contribute to excessive diagnosis of asymptomatic and nonfatal thyroid cancer.

\section{Conclusion}

Our findings suggest that a higher number of thyroid fine-needle aspiration biopsies in each $\mathrm{Si}-\mathrm{Gun}-\mathrm{Gu}$ is positively associated with increased diagnoses of thyroid cancer in South Korean patients. We recommend that healthcare professionals and policy makers implement alternate preventive strategies to thyroid fine-needle aspiration biopsies during health checkup program visits.

\section{Additional file}

Additional file 1: General characteristics of study population at baseline Provides a baseline characteristics of study population. (DOCX $16 \mathrm{~kb}$ )

\section{Abbreviation}

ANOVA: Analysis of variance; Cl: Confidence interval; EDI: Electronic data interchange; GEE: Generalized estimated equations; ICD: International classification of diseases; NHI: National Health Insurance; NHIS: National
Health Insurance Service; QIC: Quasi-likelihood under the independence criterion; RR: Relative risk; SD: Standard deviation

\section{Acknowledgements}

Not applicable.

\section{Funding}

This study was supported by a grant from the National R\&D Program for Cancer Control, Ministry of Health and Welfare, Republic of Korea (No. 1420230). The funding source had no role in any of the following: the design and conduct of the study; the collection, preparation, management, analysis, and interpretation of data; and the review and approval of the manuscript.

\section{Availability of data and materials}

The datasets analyzed during the current study are available in the NHIS. For obtaining the NHIS National Sampling Cohort, go to the following web site, and submit the application form (https://nhiss.nhis.or.kr/bd/ab/bdaba021eng.do). The committee will evaluate that, and notice the determination of deliberation within 25 days from the data of application. And then, applicants who passed deliberation can use this data after payment of fee.

\section{Authors' contributions}

YJC, and DYK designed the study, collected data, performed statistical analyses, and wrote the manuscript. These authors contributed equally to this work as co-first author. ECP, and KTH contributed to the discussion and reviewed and edited the manuscript. KTH is the guarantor of this work and as such, had full access to all the data in the study and takes responsibility for the integrity of the data and the accuracy of the data analysis. All authors have read and approved the final version of this manuscript. The text in this document has been checked by at least two professional editors who are native English speakers.

\section{Competing interests}

The authors declare that they have no competing interests.

\section{Consent for publication}

Not applicable.

\section{Ethics approval and consent to participate}

The data used in our study comprised details about patients' utilization of thyroid fine-needle aspiration biopsy and diagnosis of thyroid cancer in 
South Korea. This study was approved by the Institutional Review Board, Yonsei University Graduate School of Public Health (approval no. 2-1040939-AB$\mathrm{N}-01-2014-239)$. The informed consents of each patient was waived, because patient information was routinely collected based on claims data and anonymized prior to analysis.

\section{Author details}

${ }^{1}$ Premedical Courses, Yonsei University College of Medicine, Seoul, Republic of Korea. ${ }^{2}$ Institute of Health Services Research, Yonsei University, Seoul, Republic of Korea. ${ }^{3}$ Department of Preventive Medicine, Yonsei University College of Medicine, Seoul, Republic of Korea. ${ }^{4}$ Department of Public Health, Graduate School, Yonsei University, Seoul, Republic of Korea.

Received: 23 September 2016 Accepted: 1 February 2017 Published online: 07 February 2017

\section{References}

1. Kwon S. Thirty years of national health insurance in South Korea: lessons for achieving universal health care coverage. Health Policy Plan. 2009;24(1):63-71.

2. Song YJ. The South Korean health care system. JMAJ. 2009:52(3):206-9.

3. Jang S-I, Nam J-M, Choi J, Park E-C. Disease management index of potential years of life lost as a tool for setting priorities in national disease control using OECD health data. Health Policy. 2014;115(1):92-9.

4. Oh C-M, Won Y-J, Jung K-W, Kong H-J, Cho H, Lee J-K, Lee DH, Lee KH. Cancer Statistics in Korea: Incidence, Mortality, Survival, and Prevalence in 2013. Cancer Res Treat. 2016;48(2):436.

5. Han K-T, Kim J, Nam CM, Moon KT, Lee SG, Kim SJ, Ju YJ, Kwon JA, Kim SJ, Kim W. Association between reduction in copayment and gastric cancer patient concentration to the capital area in South Korea: NHI cohort 2003-2013. Health Policy. 2016;120(6):580-89.

6. Ahn HS, Kim HJ, Welch HG. Korea's thyroid-cancer" epidemic": screening and overdiagnosis. N Engl J Med. 2014;371(19):1765-7.

7. Lee J-H, Shin SW. Overdiagnosis and screening for thyroid cancer in Korea. Lancet. 2014;384(9957):1848.

8. Welch HG, Black WC. Overdiagnosis in cancer. J Natl Cancer Inst. 2010; 102(9):605-13.

9. Vecchia C, Malvezzi M, Bosetti C, Garavello W, Bertuccio P, Levi F, Negri E. Thyroid cancer mortality and incidence: a global overview. Int J Cancer. 2015:136(9):2187-95.

10. Ferlay J, Soerjomataram I, Dikshit R, Eser S, Mathers C, Rebelo M, Parkin DM, Forman D, Bray F. Cancer incidence and mortality worldwide: sources, methods and major patterns in GLOBOCAN 2012. Int J Cancer. 2015;136(5):E359-86.

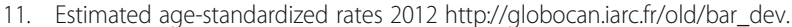
asp?population $1=102410 \&$ population $2=222900 \&$ sex $=0 \&$ statistic $=2 \&$ number $=$ $10 \&$ window $=1 \& \mathrm{grid}=1 \&$ color $1=5 \&$ color $1 \mathrm{e}=\&$ color $2=4 \&$ color $2 \mathrm{e}=\&$ submit $=$ \%C2\%A0Execute. Accessed 24 Aug 2016.

12. Cancer Statistics 2000-13 http://kosis.kr/statHtml/statHtml.do?orgld= 117\&tblld=DT_117N_A00025\&conn_path=12. Accessed 24 Aug 2016.

13. Davies $L$, Welch $H G$. Current thyroid cancer trends in the United States. JAMA Otolaryngol Head Neck Surg. 2014;140(4):317-22.

14. Davies $L$, Welch $H G$. Increasing incidence of thyroid cancer in the United States, 1973-2002. JAMA. 2006;295(18):2164-7.

15. Morris LG, Sikora AG, Tosteson TD, Davies L. The increasing incidence of thyroid cancer: the influence of access to care. Thyroid. 2013;23(7):885-91.

16. Cooper DS, Doherty GM, Haugen BR, Kloos RT, Lee SL, Mandel SJ, Mazzaferri EL, Mclver B, Pacini F, Schlumberger M. Revised American Thyroid Association management guidelines for patients with thyroid nodules and differentiated thyroid cancer: the American Thyroid Association (ATA) guidelines taskforce on thyroid nodules and differentiated thyroid cancer. Thyroid. 2009;19(11):1167-214.

17. National Health Insurance Service Ilsan Hospital. The treds of thyroid cancer in South Korea during 2003-2012. 2014

18. Belfiore A, La Rosa GL, La Porta GA, Giuffrida D, Milazzo G, Lupo L, Regalbuto C, Vigneri R. Cancer risk in patients with cold thyroid nodules: relevance of iodine intake, sex, age, and multinodularity. Am J Med. 1992;93(4):363-9.

19. Kim K-M, Park D. Impacts of urban economic factors on private tutoring industry. Asia Pac Educ Rev. 2012;13(2):273-80.

20. Hanley JA, Negassa A, Forrester JE. Statistical analysis of correlated data using generalized estimating equations: an orientation. Am J Epidemiol. 2003;157(4):364-75.
21. Pan $\mathbf{W}$. Akaike's information criterion in generalized estimating equations. Biometrics. 2001:57(1):120-5.

22. Brito JP, Morris JC, Montori VM. Thyroid cancer: zealous imaging has increased detection and treatment of low risk tumours. 2013.

23. Cooper DS, Doherty GM, Haugen BR, Kloos RT, Lee SL, Mandel SJ, Mazzaferri EL, Mclver B, Sherman SI, Tuttle RM. Management guidelines for patients with thyroid nodules and differentiated thyroid cancer: The American Thyroid Association Guidelines Taskforce. Thyroid. 2006;16(2):109-42.

24. British Thyroid Association: Guidelines for the management of thyroid cancer (Perros P, ed) 2nd edition. Report of the Thyroid Cancer Guideline Update Group. London: Royal College of Physicians; 2007.

25. Yi KH, Park YJ, Koong S-S, Kim J-H, Na DG, Ryu J-S, Park SY, Park IA, Baek C$H$, Shong YK, et al. Revised Korean Thyroid Association Management Guidelines for Patients with Thyroid Nodules and Thyroid Cancer [Korean] Korean Thyroid Assoc. 2010;3(2):65-96.

\section{Submit your next manuscript to BioMed Central and we will help you at every step:}

- We accept pre-submission inquiries

- Our selector tool helps you to find the most relevant journal

- We provide round the clock customer support

- Convenient online submission

- Thorough peer review

- Inclusion in PubMed and all major indexing services

- Maximum visibility for your research

Submit your manuscript at www.biomedcentral.com/submit
) Biomed Central 